\title{
Selective antegrade cerebral perfusion via right axillary artery cannulation reduces morbidity and mortality after proximal aortic surgery
}

\author{
Michael E. Halkos, MD, ${ }^{\mathrm{a}}$ Faraz Kerendi, MD, ${ }^{\mathrm{a}}$ Richard Myung, MD, ${ }^{\mathrm{a}}$ Patrick Kilgo, MSc, ${ }^{\mathrm{b}}$ \\ John D. Puskas, MD, ${ }^{\mathrm{a}}$ and Edward P. Chen, MD ${ }^{\mathrm{a}}$
}

\begin{abstract}
Introduction: Selective antegrade cerebral perfusion is a well-described neuroprotective technique used in proximal aortic surgery. This study investigated whether selective antegrade cerebral perfusion is associated with improved outcomes in both emergency and elective settings compared with deep hypothermic circulatory arrest alone.
\end{abstract}

\begin{abstract}
Methods: Retrospective review was performed for all cases of proximal aortic surgery between January 2004 and May 2007. Of these 271 patients, 105 had emergency and 166 had elective operation. Selection bias was controlled using propensity scoring methods. Multivariable logistic regression analysis was used to model adverse outcomes as a function of selective antegrade cerebral perfusion, emergency status, and their interaction, adjusted for the propensity score. Adjusted odds ratios were formulated with $95 \%$ confidence intervals.
\end{abstract}

\begin{abstract}
Results: Operative mortality occurred in $12.1 \%(33 / 271)$ of patients: $8.8 \%(18 / 205)$ in patients with selective antegrade cerebral perfusion versus $22.7 \%(15 / 66)$ in those with deep hypothermic circulatory arrest alone $(P=.003)$. Temporary neurologic dysfunction occurred in 5.9\% (15/255) of patients: $4.5 \%(9 / 198)$ in selective antegrade cerebral perfusion versus $10.5 \%(6 / 57)$ in deep hypothermic circulatory arrest alone $(P=.09)$. Stroke occurred in $4.3 \%(11 / 255)$ of patients with no difference between groups. In the elective setting, selective antegrade cerebral perfusion was associated with a significant decrease in operative mortality compared with deep hypothermic circulatory arrest alone. Overall, selective antegrade cerebral perfusion was associated with shorter intensive care unit and ventilator times and fewer renal and pulmonary complications. Significant multivariable predictors of operative mortality were emergency status, previous coronary surgery, and cardiopulmonary bypass time.
\end{abstract}

Conclusions: Use of selective antegrade cerebral perfusion confers a survival advantage during proximal aortic surgery that is most apparent in the elective setting. Improved resource utilization and fewer pulmonary and renal complications were observed in patients with selective antegrade cerebral perfusion.

Neuroprotective strategies during proximal aortic surgery include deep hypothermia alone (DHCA) or in conjunction with antegrade and/or retrograde cerebral perfusion. Cerebral complications after proximal aortic surgery may be a consequence of global ischemia during circulatory arrest or embolic events associated with atheromatous debris or thrombus. ${ }^{1,2}$

The optimal method of arterial cannulation and perfusion as well as cerebral protection remains controversial, and several reports exist documenting the safety and efficacy

\footnotetext{
From the Clinical Research Unit, Division of Cardiothoracic Surgery, ${ }^{\mathrm{a}}$ and the Rollins School of Public Health, ${ }^{\mathrm{b}}$ Emory University School of Medicine, Atlanta, Ga. Presented at the Annual Meeting of the American Association of Thoracic Surgeons, May 10 to 14, 2008, San Diego, Calif.

Received for publication May 2, 2008; revisions received May 21, 2009; accepted for publication July 20, 2009; available ahead of print Sept 16, 2009.

Address for reprints: Edward P. Chen, MD, Assistant Professor, Division of Cardiothoracic Surgery, The Emory Clinic, 1365 Clifton Rd, Suite A2236, Atlanta, GA 30322 (E-mail: edward.p.chen@emory.edu).

J Thorac Cardiovasc Surg 2009;138:1081-9

$0022-5223 / \$ 36.00$

Copyright (C) 2009 by The American Association for Thoracic Surgery

doi:10.1016/j.jtcvs.2009.07.045
}

of a variety of approaches. ${ }^{2-10}$ Avoiding femoral artery cannulation may reduce the risk of retrograde thromboembolism from atheromatous debris in the thoracic and abdominal aorta. ${ }^{11}$ Direct cannulation of the ascending aorta can be complicated by the presence of dissection, aneurysm, and thrombus, which could potentially also cause thromboembolic events or malperfusion. Use of the right axillary artery not only provides antegrade arterial perfusion during cardiopulmonary bypass, but also allows for continuous antegrade cerebral perfusion during hypothermic circulatory arrest, thereby minimizing global cerebral ischemia.

It is presently unclear whether the use of these various strategies results in different outcomes in emergency surgery as well as the elective setting. The purpose of this study was to evaluate the impact of selective antegrade cerebral perfusion (SACP) on postoperative outcomes and to identify factors influencing morbidity and mortality in both elective as well as emergency settings.

\section{PATIENTS AND METHODS \\ Patient Characteristics}

Between January 2004 and May 2007, 271 patients had operations on the proximal thoracic aorta and/or aortic arch at the 3 primary hospitals in the 


\author{
Abbreviations and Acronyms \\ $\mathrm{AOR}=$ adjusted odds ratio \\ $\mathrm{CABG}=$ coronary artery bypass grafting \\ $\mathrm{CI} \quad=$ confidence interval \\ DHCA $=$ deep hypothermia alone \\ SACP $=$ selective antegrade cerebral perfusion \\ $\mathrm{TND}=$ temporary neurologic dysfunction
}

Emory Healthcare System. All patients with operations involving the ascending aorta using DHCA with or without SACP during this study period were included. Patients having concomitant procedures involving the aortic root and/or aortic arch were also included. Patients having isolated aortic root reconstruction without the use of DHCA were excluded. Medical records were retrospectively reviewed for pre-, intra-, and postoperative variables. In the study group, 105 patients had emergency operations for acute type A aortic dissection and 166 patients had elective surgery for other thoracic aortic pathology, the majority being degenerative aneurysmal disease. The diagnosis of acute dissection or aneurysm was confirmed by preoperative computed tomography scan or transesophageal echocardiography in all patients. Patients having DHCA without additional cerebral perfusion strategies were classified in the DHCA group and compared with patients who received SACP during the period of circulatory arrest (SACP group). Demographics and perioperative variables are listed in Tables 1 and 2. Definitions were according to the Society of Thoracic Surgeons National Database specifications (http://www.sts.org/documents/pdf/AdultCVData Specifications2.61.pdf).

DHCA was used for cerebral protection in 66 patients. SACP via the right axillary artery was used with moderate hypothermia in 205 patients. Right axillary artery use for SACP was aborted because of small size in 1 patient, severe atherosclerosis in 1 patient, and presence of dissection in 3 patients. Retrograde cerebral perfusion was used infrequently and therefore not included in the analysis. The year of operation did not influence the

TABLE 1. Preoperative patient characteristics

\begin{tabular}{lccc}
\hline \multicolumn{1}{c}{ Risk factor } & $\begin{array}{c}\text { SACP } \\
(\mathbf{n}=\mathbf{2 0 5}), \boldsymbol{\%}\end{array}$ & $\begin{array}{c}\text { DHCA } \\
(\mathbf{n}=\mathbf{6 6}), \boldsymbol{\%}\end{array}$ & $\boldsymbol{P}$ value \\
\hline Emergency & $65(31.7)$ & $40(60.6)$ & $<.001$ \\
Age (mean \pm SD) & $57.8 \pm 14.1$ & $54.5 \pm 13.9$ & .102 \\
Female gender & $62(30.2)$ & $16(24.2)$ & .35 \\
Cerebrovascular disease & $21(10.2)$ & $9(13.6)$ & .44 \\
History of cerebrovascular & $14(6.8)$ & $7(10.6)$ & .32 \\
$\quad$ accident & & & \\
NYHA class 4 & $21(10.2)$ & $25(37.9)$ & $<.001$ \\
Diabetes mellitus & $26(12.7)$ & $7(10.6)$ & .65 \\
Hypertension & $162(79.0)$ & $51(77.3)$ & .76 \\
Peripheral vascular disease & $12(5.6)$ & $7(10.6)$ & .19 \\
Renal failure & $13(6.3)$ & $7(10.6)$ & .25 \\
Renal failure-dialysis dependent & $5(2.4)$ & $3(4.6)$ & .38 \\
Congestive heart failure & $52(25.4)$ & $16(24.2)$ & .85 \\
Cardiac tamponade & $2(1.0)$ & $3(4.6)$ & .06 \\
Redo sternotomy & $35(17.1)$ & $16(24.2)$ & .20 \\
Previous CABG & $12(4.4)$ & $7(10.6)$ & .19 \\
Previous cardiovascular & $62(30.2)$ & $21(31.8)$ & .81 \\
$\quad$ intervention & & & \\
Previous valve surgery & $20(9.8)$ & $10(15.2)$ & .22 \\
\hline CABG, Cor
\end{tabular}

$C A B G$, Coronary artery bypass grafting; $D H C A$, deep hypothermic circulatory arrest; NYHA, New York Heart Association heart failure classification; $S A C P$, selective antegrade cerebral perfusion; $S D$, standard deviation. method of cerebral protection. Femoral artery cannulation was used in 26 patients, central aortic cannulation in 27 patients, and axillary artery cannulation in 218 patients. In 11 patients having reoperations, the axillary artery was used for systemic arterial perfusion, but SACP was not used because of inability to occlude the innominate artery.

This study was approved by the Institutional Review Board at Emory University in compliance with HIPAA regulations and the Declaration of Helsinki. The Institutional Review Board waived the need for individual patient consent.

\section{Operative Technique}

Anesthetic induction was achieved with standard techniques including administration of sodium pentothal, isofluorane, fentanyl, and muscle relaxant. Invasive monitoring included the use of a pulmonary artery catheter and either a left radial or femoral arterial line to allow measurement of systemic perfusion pressures during cardiopulmonary bypass. Transcutaneous cerebral oximetry (INVOS 3100-SD; Troy, Mich) and electroencephalogram monitoring were routinely performed in all circulatory arrest cases, with or without SACP. Intraoperative transesophageal echocardiography was used in all patients.

In patients having cerebral protection with DHCA, arterial cannulation was achieved via the femoral artery or ascending aorta using epiaortic ultrasound and transesophageal echocardiography guidance. A 3-stage central cannula (Medtronic Corp, Minneapolis, Minn) placed in the right atrium was used for systemic venous return in the majority of patients. Femoral venous cannulation was used in 7 patients.

In patients having cerebral protection via SACP, right axillary artery exposure was achieved with a deltopectoral groove incision. After division of the pectoralis minor muscle, the brachial plexus was carefully identified and avoided. After administration of $5000 \mathrm{U}$ of heparin, a side-biting clamp was placed across the axillary artery. An 8-mm Gelweave graft (Vascutek; Terumo, Ann Arbor, Mich) was sewn end-to-side to the axillary artery using a running 6-0 polypropylene suture. The graft was then cannulated with a 22F Elongated Arterial Cannula (Medtronic) and secured. An additional arterial line was attached to a side port to measure cerebral perfusion

TABLE 2. Overview of operative variables

\begin{tabular}{|c|c|c|c|}
\hline Variable & $\begin{array}{c}\text { SACP } \\
(n=205), \%\end{array}$ & $\begin{array}{c}\text { DHCA } \\
(\mathrm{n}=66), \%\end{array}$ & $P$ value \\
\hline $\begin{array}{l}\text { Cross clamp time (mean } \pm \\
\text { SD), min }\end{array}$ & $139.1 \pm 58.2$ & $128.9 \pm 52.3$ & .20 \\
\hline $\begin{array}{l}\text { Perfusion time (mean } \pm \mathrm{SD} \text { ), } \\
\quad \min \end{array}$ & $183.3 \pm 64.0$ & $218.2 \pm 75.9$ & $<.001$ \\
\hline $\begin{array}{l}\text { Circulatory arrest time (mean } \\
\quad \pm \mathrm{SD} \text { ), min }\end{array}$ & $26.2 \pm 12.2$ & $26.0 \pm 8.5$ & .90 \\
\hline $\begin{array}{l}\text { Lowest core temp (mean } \pm \\
\text { SD), }{ }^{\circ} \mathrm{C}\end{array}$ & $23.2 \pm 4.2$ & $19.8 \pm 3.8$ & $<.001$ \\
\hline Postoperative IABP (\%) & $13(6.3)$ & $9(13.6)$ & .06 \\
\hline $\begin{array}{l}\text { Root reconstruction } \pm \text { valve } \\
\text { sparing }(\%)\end{array}$ & $69(33.7)$ & $19(28.8)$ & .46 \\
\hline CABG $(\%)$ & $52(25.4)$ & $19(28.8)$ & .71 \\
\hline $\begin{array}{l}\text { Resuspension/repair of aortic } \\
\text { valve }(\%)\end{array}$ & $68(33.2)$ & $28(42.4)$ & .25 \\
\hline $\begin{array}{l}\text { Mitral valve repair/ } \\
\text { replacement }(\%)\end{array}$ & $7(3.4)$ & $5(7.6)$ & .18 \\
\hline Aortic arch replacement $(\%)$ & $9(4.4)$ & 0 & .08 \\
\hline Aortic valve replacement $(\%)$ & $45(22.0)$ & $7(10.6)$ & .031 \\
\hline Homograft $(\%)$ & $2(1.0)$ & $4(6.1)$ & .018 \\
\hline
\end{tabular}

$\overline{D H C A}$, Deep hypothermic circulatory arrest; $C A B G$, coronary artery bypass grafting; $I A B P$, intra-aortic balloon pump; $S A C P$, selective antegrade cerebral perfusion; $S D$, standard deviation. 
pressures during circulatory arrest. In addition, other routine measures were used, included topical head cooling and placing patients in the Trendelenburg positioning prior to aortotomy.

All patients were approached via median sternotomy incision. In patients with SACP, the innominate artery was isolated proximal to the takeoff of the right subclavian artery to allow for antegrade perfusion of the right common carotid artery. Systemic cooling was variable and depended on the mode of cerebral protection as well as the anticipated duration of the circulatory arrest period and complexity of the arch procedure. In general, patients in the DHCA group were cooled to a goal temperature of $18^{\circ} \mathrm{C}$, and patients in the SACP group were cooled to moderate levels of hypothermia. Prior to circulatory arrest in patients in the SACP group, the innominate artery was occluded proximally and cerebral perfusion initiated at $18{ }^{\circ} \mathrm{C}$ at a rate of $10 \mathrm{~mL} . \mathrm{kg}^{-1} \cdot \mathrm{min}^{-1}$ and adjusted to maintain cerebral perfusion pressures of $60 \mathrm{~mm} \mathrm{Hg}$. In patients having DHCA, adjunctive neuroprotective measures varied and included the administration of intravenous sodium pentothal, solumedrol, and lidocaine. Myocardial protection was achieved with cold blood cardioplegic solution, delivered in both an antegrade and retrograde manner.

The ascending aorta was not routinely clamped during the cooling period except in the presence of severe aortic insufficiency to avoid ventricular distention. Left ventricular decompression was achieved with a vent placed via the right superior pulmonary vein. In all cases of hemi-arch replacement, distal aortic reconstruction was performed with an open beveled anastomosis to the undersurface of the aortic arch using a Gelweave graft (Vascutek; Terumo). Total arch replacement was defined as separate reimplantation of all arch vessels. Felt reinforcement of the distal aortic anastomosis was performed in all cases. Following the circulatory arrest period, vigorous deairing maneuvers were performed and cardiopulmonary bypass was slowly reinstituted via a separate cannula in the graft. Perfusion via the right subclavian artery in SACP cases was discontinued after adequate flows were confirmed. Proximal aortic procedures as well as any coronary or valve intervention were performed during the rewarming period.

\section{Statistical Analysis}

Operative mortality included in-hospital and 30-day mortality. Permanent postoperative stroke was defined as a new and permanent focal neurologic deficit with or without evidence of cerebral infarction on computed tomography or magnetic resonance imaging and was confirmed by a neurologist. Temporary neurologic dysfunction (TND) was defined as postoperative confusion, delirium, obtundation, or transient focal deficits (resolution within 24 hours) with negative brain computed tomography or magnetic resonance imaging scans. ${ }^{12}$ In this analysis, patients who died in the operating room or within 24 hours after surgery were excluded from the analyses of postoperative stroke or TND only if neurologic assessment in these patients was not possible. All identifiable patients who died from complications of stroke or TND were included.

Data were complete for the critical risk factors such as SACP and emergency status as well as for each primary postoperative outcome (operative mortality, permanent stroke, and TND). Data were missing on the following variables: last creatinine level $(n=6 ; 2.2 \%)$ and ejection fraction $(n=69$; $25.5 \%$ ). To prevent patients with missing data from being excluded from the analysis, multiple imputation methods described by Molenberghs and Kenward ${ }^{13}$ were used to impute values. The goal of multiple imputations is not to replace data with plausible values but rather to impute with values that will maintain the covariance structure so that valuable data that are missing will not be omitted from analysis.

To adjust for the potential of selection bias in this study group, a propensity scoring approach was used to balance the patient group with respect to its preoperative characteristics. A total of 32 variables, including year of surgery, surgeon identity, and concomitant procedures, were used to estimate the predicted probability of being treated with SACP; this is the propensity score. Once formulated, the propensity score was used as a single covariate in a multiple logistic regression model that also includes the primary vari- ables of interest: SACP, emergency status, and their interaction. A statistically significant interaction would indicate that the effect of SACP is different for patients having emergency versus elective surgery. For unadjusted comparisons, 2-sample $t$ tests and chi-square tests were performed for continuous and categorical outcomes, respectively.

For each primary outcome, adjusted odds ratios (AORs) with associated 95\% confidence intervals (CIs) for variables of interest were computed for comparisons of combinations of SACP status (SACP or DCHA) and emergency status (emergency or elective). Four preplanned comparisons for each of the 4 multiple logistic regression models were of interest: (1) elective SACP versus emergency SACP; (2) elective DHCA versus emergency DHCA; (3) elective SACP versus elective DHCA (AOR); and (4) emergency SACP versus emergency DHCA.

Univariable associations between 15 preoperative and intraoperative variables and operative mortality were determined using odds ratios via logistic regression analysis. These variables were also considered simultaneously in a multivariable logistic model that was fit without regard to issues of confounding or multicollinearity. The variables included in this analysis were emergency status, use of SACP, age $>65$, renal insufficiency, diabetes, redo sternotomy, previous $\mathrm{CABG}$, circulatory arrest time $>30$ minutes, perfusion time, crossclamp time, lowest core temperature, aortic root procedure, aortic valve replacement, total arch replacement, and concomitant CABG.

The data were analyzed with SAS Version 9.1 (Cary, NC) and STATA 9.0. All statistical tests were evaluated at the .05 alpha level. All comparisons and model terms were preplanned.

\section{RESULTS}

Although circulatory arrest time was comparable between groups ( 26 minutes), patients in the DHCA group underwent systemic cooling to a lower temperature than patients in the SACP group $\left(23.2^{\circ} \mathrm{C} \pm 4.2^{\circ} \mathrm{C}\right.$ vs $19.8^{\circ} \mathrm{C} \pm 3.8^{\circ} \mathrm{C}$, $P<.001)$. In addition, cardiopulmonary bypass times were longer for the DHCA group (218.2 \pm 75.9 vs 183.3 \pm 64.0 minutes, $P<.001$ ). Concomitant procedures (Table 2) including aortic root reconstruction were performed in 88 $(32.5 \%)$ patients, aortic valve replacement in $52(19.2 \%)$ patients, and coronary artery bypass grafting (CABG) in $71(26.2 \%)$ patients. Fifty-one $(18.8 \%)$ patients had prior cardiac surgery via median sternotomy (19 patients with previous $\mathrm{CABG}$ ) and had reoperations. In 6 patients having elective surgery, a homograft conduit was used in the setting of prosthetic valve endocarditis with an aortic abscess. In patients with SACP, there was a significantly higher incidence of aortic root reconstruction and aortic valve replacement without root reconstruction. In addition, 9 patients had concomitant total aortic arch replacement in the SACP group compared with no patients in the DHCA group. Of the 105 patients who presented with acute type A aortic dissection, $2(1.9 \%)$ presented with preoperative neurologic deficits, and $5(4.8 \%)$ presented with cardiac tamponade secondary to free aortic rupture, including 2 patients who were taken to the operating room with ongoing cardiopulmonary resuscitation.

\section{Operative Mortality}

In this study, overall operative mortality was $12.1 \%$ (33/ 271). Operative mortality was $7.2 \%(12 / 166)$ in patients having elective surgery on the ascending thoracic aorta 
TABLE 3. Outcomes among all patients

\begin{tabular}{lccc}
\hline \multicolumn{1}{c}{ Outcomes } & $\begin{array}{c}\text { SACP } \\
(\mathbf{n = 2 0 5}), \boldsymbol{\%}\end{array}$ & $\begin{array}{c}\text { DHCA } \\
(\mathbf{n}=\mathbf{6 6}), \boldsymbol{\%}\end{array}$ & $\boldsymbol{P}$ value \\
\hline Operative mortality & $18(8.8)$ & $15(22.7)$ & .003 \\
Temporary neurologic & $9 / 198(4.5)$ & $6 / 57(10.5)$ & .09 \\
$\quad$ dysfunction* & & & \\
Permanent stroke* & $8 / 198(4.0)$ & $3 / 57(5.3)$ & .69 \\
Reintubated & $19(9.3)$ & $8(12.1)$ & .05 \\
Renal failure & $23(11.2)$ & $16(24.2)$ & .01 \\
Total hours ICU & $115 \pm 151$ & $177 \pm 231$ & .05 \\
$\quad$ (mean \pm SD) & & & \\
Postoperative ventilator & $61.7 \pm 116.2$ & $131.5 \pm 234.8$ & .03 \\
$\quad$ hours (mean \pm SD) & & & \\
LOS $>$ 7 d & $94(45.9)$ & $35(53.0)$ & .31 \\
Pulmonary complications & $24(11.7)$ & $14(21.2)$ & .05 \\
$\quad$ (ARDS, pneumonia, & & & \\
$\quad$ pulmonary embolism) & & & \\
\hline
\end{tabular}

ARDS, Acute respiratory distress syndrome; $D H C A$, deep hypothermic circulatory arrest; $I C U$, intensive care unit; $L O S$, length of stay; $S A C P$, selective antegrade cerebral perfusion; $S D$, standard deviation. *Operative or early postoperative deaths were excluded.

and/or aortic arch and 20\% (21/105) in patients undergoing emergency repair of type A aortic dissection.

Overall outcomes in patients according to cerebral protection strategy are listed in Tables 3 and 4. In all patients, operative mortality was significantly lower in patients having SACP versus those having DHCA $(8.8 \%$ vs $22.7 \%)$. The difference in operative mortality can be explained by the differences seen in patients who were operated on electively $(4.3 \%$ vs $23.1 \%, P<.001)$. AOR comparisons between combinations of SACP and emergency status are listed in Table 5. In this model, the impact of pre- and intraoperative variables on mortality was considered. There was a significant reduction (AOR 0.22) in operative mortality among patients having elective surgery who had SACP compared with patients who had DHCA. Furthermore, a signifi- cant mortality difference was observed between emergency and elective SACP groups that was not observed between emergency and elective DHCA groups.

Emergency status (AOR 3.21, CI 1.58, 6.84), preoperative renal failure (AOR 4.66, CI 1.71, 12.73), previous CABG (AOR 6.6, CI 2.43, 17.95), cardiopulmonary bypass time (AOR 1.009, CI 1.004, 1.014), and concomitant CABG (AOR 2.71, CI 1.28, 5.72) emerged as significant $(P<.05)$ univariable predictors of operative mortality. In contrast, SACP was protective and associated with reduced operative mortality (AOR 0.33, CI 0.15, 0.69). In the multivariable analysis, emergency status (AOR 3.57, CI 1.13, 11.3), previous CABG (AOR, 11.84, CI 1.33, 105.7), and cardiopulmonary bypass time (AOR 1.018, CI 1.004, 1.032) were significant $(P<0.05)$ predictors of operative mortality.

Of the 33 operative deaths, 8 patients were older than 65 years. Intraoperative death occurred in 4 patients with SACP and 5 patients with DHCA. Postoperative cardiogenic shock was the cause of death in 3 patients in each group. Of the patients who died from multisystem organ failure (6 in each group), 3 in the SACP group and 4 in the DHCA group had bowel ischemia or necrosis that precipitated their deaths. In the DHCA group, 1 patient who died of multisystem organ failure also had a permanent stroke.

Of the 18 patients who had SACP and died, 12 had emergency operations, 6 had reoperations, 9 had concomitant CABG, 6 had previously had CABG, and 2 had concomitant total arch replacement. In the 15 patients who had DHCA and died, 9 had emergency operations, 4 had reoperations, 6 had concomitant $\mathrm{CABG}$, and 2 had previously had CABG. Of the 6 deaths in the elective DHCA group, 3 patients had reoperative cardiac surgery, 3 patients required aortic replacement intraoperatively because of injury or severe calcification, 2 patients had prosthetic aortic graft infections, and 1 patient had a chronic type A dissection.

TABLE 4. Outcomes among patients according to emergency or elective status

\begin{tabular}{|c|c|c|c|c|c|c|}
\hline Outcomes & $\begin{array}{c}\text { Elective SACP } \\
(n=140)\end{array}$ & $\begin{array}{c}\text { Elective DHCA } \\
(\mathrm{n}=\mathbf{2 6})\end{array}$ & $P$ value & $\begin{array}{c}\text { Emergency SACP } \\
(n=65), \%\end{array}$ & $\begin{array}{c}\text { Emergency DHCA } \\
(n=40), \%\end{array}$ & $P$ value \\
\hline Operative mortality & $6(4.3)$ & $6(23.1)$ & $<.001$ & $12(18.5)$ & $9(22.5)$ & .62 \\
\hline $\begin{array}{l}\text { Temporary neurologic } \\
\text { dysfunction* }\end{array}$ & $2 / 137(1.5)$ & $1 / 21(4.8)$ & .30 & $7 / 61(11.5)$ & $5 / 36(13.9)$ & .78 \\
\hline Permanent stroke* & $4 / 137(2.9)$ & $0(0)$ & .44 & $4 / 61(6.6)$ & $3 / 36(8.3)$ & .79 \\
\hline Reintubated & $5(3.6)$ & $2(7.7)$ & .34 & $14(21.5)$ & $6(15.0)$ & .41 \\
\hline Renal failure & $8(5.7)$ & $4(15.4)$ & .08 & $15(23.1)$ & $12(30.0)$ & .43 \\
\hline $\begin{array}{l}\text { Total hours ICU } \\
(\text { mean } \pm \mathrm{SD})\end{array}$ & $79.3 \pm 116.4$ & $133.2 \pm 165.6$ & .15 & $195.5 \pm 188.3$ & $202.4 \pm 259.3$ & .89 \\
\hline $\begin{array}{l}\text { Postoperative ventilator } \\
\text { hours (mean } \pm \mathrm{SD})\end{array}$ & $34.5 \pm 73.5$ & $71.6 \pm 127.4$ & .20 & $123.1 \pm 163.4$ & $166.3 \pm 274.4$ & .38 \\
\hline $\operatorname{LOS}>7 \mathrm{~d}$ & $49(35.0)$ & $8(30.8)$ & .68 & $45(69.2)$ & $27(67.5)$ & .85 \\
\hline $\begin{array}{l}\text { Pulmonary complications } \\
\text { (ARDS, pneumonia, } \\
\text { pulmonary embolism) }\end{array}$ & $5(3.6)$ & $3(11.5)$ & .08 & $19(29.2)$ & $11(27.5)$ & .85 \\
\hline
\end{tabular}

$A R D S$, Acute respiratory distress syndrome; $D H C A$, deep hypothermic circulatory arrest; $I C U$, intensive care unit; $L O S$, length of stay; $S A C P$, selective antegrade cerebral perfusion; $S D$, standard deviation. *Operative or early postoperative deaths were excluded. 
TABLE 5. Adjusted odds ratio comparisons (95\% confidence intervals) between combinations of SACP and emergency status

\begin{tabular}{llccc}
\hline \multicolumn{1}{c}{ Outcome } & $\begin{array}{c}\text { Elective SACP vs } \\
\text { emergency SACP } \\
\text { (AOR) }\end{array}$ & $\begin{array}{c}\text { Elective DHCA vs } \\
\text { emergency DHCA } \\
\text { (AOR) }\end{array}$ & $\begin{array}{c}\text { Elective SACP vs } \\
\text { elective DHCA } \\
\text { (AOR) }\end{array}$ & $\begin{array}{c}\text { Emergency SACP vs } \\
\text { emergency DHCA } \\
\text { (AOR) }\end{array}$ \\
\hline Operative mortality & $0.24(0.08,0.67)^{*}$ & $1.48(0.42,5.23)$ & $0.22(0.06,0.83)^{*}$ & $1.41(0.43,4.59)$ \\
TND $\dagger$ & $0.12(0.02,0.60)$ & $0.32(0.03,3.22)$ & $0.30(0.03,3.68)$ & $0.82(0.18,3.77)$ \\
TND or stroke $\dagger$ & $0.22(0.08,0.64)$ & $0.19(0.02,1.77)$ & $0.99(0.11,8.96)$ & $0.86(0.24,3.03)$ \\
\hline
\end{tabular}

$A O R$, Adjusted odds ration; $D H C A$, deep hypothermic circulatory arrest; $S A C P$, selective antegrade cerebral perfusion; $T N D$, transient neurologic dysfunction. $* P<.05$. $\dagger$ Patients who died before neurologic assessment were excluded.

\section{Neurologic Outcomes}

Sixteen patients (7 having SACP, 9 having DHCA) died either in the operating room or within 24 hours, which precluded a neurologic assessment. Therefore, these patients were excluded from the analysis of neurologic outcomes. Neurologic raw outcomes data are listed in Tables 3 and 4. Two patients presented with acute preoperative neurologic deficits. Overall, permanent stroke occurred in 4.3\% (11/ 255) of patients in whom neurologic assessment was possible; $27.2 \%(3 / 11)$ of these patients died. Among patients having elective operations, the incidence of stroke was only $2.5 \%$ (4/158). In contrast, patients having emergency operations had a permanent stroke incidence of 7.2\% (7/ 97), (6.6\% SACP vs $8.3 \%$ DHCA, see Table 4). There were no significant differences in permanent stroke between the SACP and DHCA groups in any of the comparisons. In the univariable and multivariable analysis, no significant predictors of postoperative stroke were identified.

TND occurred in 5.9\% (15/255) of patients; $20 \%$ (3/15) of these patients died. As seen in Table 3 , there was a strong trend toward more TND in the DHCA group $(P=.09)$. The overall incidence of TND was higher in patients having emergency operations. In the univariable and multivariable analyses, only emergency status emerged as a significant predictor of postoperative TND (AOR 7.01, CI 1.93, 25.48 and AOR 4.79, CI 1.04, 22.0, respectively, $P<.05$ ).

\section{Secondary Outcomes}

There were no local or neurovascular complications related to SACP via the right axillary artery. Additional outcomes are shown in Tables 3 and 4. Compared with patients in the DHCA group, patients in the SACP group spent less time in the intensive care unit and required a shorter duration of ventilator support. In addition, patients in the SACP group had a lower incidence of reintubation for respiratory failure, fewer pulmonary complications, and a lower incidence of renal failure.

Although mean circulatory arrest times were comparable between groups, 15 patients in the SACP group had antegrade cerebral perfusion times $>40$ minutes. Four of these patients died. Only 4 patients in the DHCA group had circulatory arrest times $>40$ minutes; however, 3 of these patients died. For patients with circulatory arrest times $\geq 30$ minutes, operative mortality was $6 / 44(13.6 \%)$ in the SACP group compared with $6 / 18(33.3 \%)$ in the DHCA group $(P=.07)$.

\section{DISCUSSION}

Described strategies for cerebral protection during operations on the proximal thoracic aorta include the use of DHCA, hypothermic circulatory arrest with retrograde cerebral perfusion, and hypothermic circulatory arrest with SACP. Although SACP via the right axillary artery was primarily used in the majority of our patients, aortic and femoral artery cannulation were also used and varied according to surgeon preference. To achieve axillary artery perfusion, our preferred strategy involves an end-to-side graft anastomosis to the right axillary artery with direct cannulation of the graft. ${ }^{14}$ In this series, there were no permanent complications associated with SACP via the right axillary artery.

Reducing neurologic complications and the associated mortality has been the impetus for previous investigations examining different methods of cerebral protection. The majority of strokes after proximal aortic surgery are generally embolic in nature and thus unlikely to be affected by different methods of cerebral protection unless the circulatory arrest time is prolonged. ${ }^{5,15}$ However, the site of cannulation may play an important role as dislodgement of atheromatous debris with subsequent cerebral embolism may occur with either aortic or femoral cannulation. ${ }^{16}$ Despite these concerns, Reece and coworkers ${ }^{3}$ and Fusco and colleagues ${ }^{3}$ reported excellent results with both central and femoral cannulation for patients with type A dissection.

SACP allows continuous brain perfusion during distal aortic or aortic arch reconstruction and prolongs the safe time of circulatory arrest. ${ }^{5,10,17,18}$ In addition, axillary artery inflow provides safe arterial access for cardiopulmonary bypass without aortic manipulation; allows for antegrade flow, which may reduce aortic emboli from aortic or femoral cannulation; and can be also used during reoperative heart surgery. ${ }^{16}$ Additional benefits include enhanced cerebral cooling and the use of moderate instead of profound hypothermia. ${ }^{7,18,19}$ Avoiding deep hypothermia likely reduces the cardiopulmonary bypass time necessary for rewarming. Despite the perceived benefit of enhanced cerebral protection with SACP, no prior report has demonstrated a reduction in postoperative stroke in a large series of 
patients. The overall incidence of permanent stroke in this report was $4.1 \%$, which compares favorably with other studies. ${ }^{2,5-7,9,10,20}$

The perceived benefit of SACP is felt to be attributed to a reduction in TND and the subsequent complications that may be associated with these deficits. ${ }^{18}$ TND appears to be a manifestation of global ischemic injury directly related to cerebral ischemic time as well as inadequate protection. ${ }^{21}$ Circulatory arrest periods as brief as 25 minutes may be associated with neuropsychologic and fine motor deficits. ${ }^{22}$ In a study comparing different modes of cerebral protection, Hagl and coworkers ${ }^{2}$ concluded that SACP was associated with a significant reduction in TND in patients with cerebral protection times between 40 and 80 minutes compared with DHCA with or without retrograde cerebral perfusion. Furthermore, retrograde cerebral perfusion did not provide any reduction in TND compared with DHCA. Di Eusanio and colleagues ${ }^{7}$ found that a circulatory arrest time of $>25$ minutes with DHCA was associated with a significant increase in TND. In a separate study, they demonstrated that SACP could be extended beyond 90 minutes without a significant increase in TND. ${ }^{5}$

In this analysis, TND occurred in $9.1 \%$ of patients with DHCA and $4.4 \%$ of patients with SACP. The need for reintubation, ventilator and intensive care unit times, and pulmonary and renal complications were significantly reduced in patients having SACP versus DHCA. The incidence of pulmonary complications may be partly explained by a reduction in TND given the trend toward reduced events in SACP patients. However, the incidence of pulmonary and renal complications could also be explained by the shorter cardiopulmonary bypass times in patients having SACP. This was due to the use of moderate instead of deep hypothermia, which required a shorter period of bypass for rewarming. Additionally, minimizing aortic manipulation with SACP by avoiding aortic or femoral cannulation may have reduced the risk of atheroemboli. In the univariable and multivariable analyses, only emergency operative status was a significant predictor of postoperative TND. However, it is plausible that other variables may have emerged as significant predictors of mortality or neurologic complications if the study size was larger. The circulatory arrest times in this report were comparable between groups and relatively short ( $<30$ minutes), thus there was not enough statistical power to differentiate neurologic outcomes in patients with prolonged circulatory arrest or SACP times.

Although the analysis did not reveal any statistically significant neurologic outcomes comparing SACP to DHCA, there was an overall survival advantage that was observed in patients having SACP that was most pronounced in patients undergoing elective repair. AOR comparisons revealed a significant reduction in operative mortality in patients with SACP having elective compared with emergency surgery. Such a difference was not observed in the DHCA groups; however, it should be noted that in the 6 elective DHCA deaths, 3 patients were having unanticipated aortic replacement for intraoperative injury or severe calcification. Concomitant and reoperative procedures in both groups were common and likely increased the complexity of these procedures in both emergency and elective settings. Our operative mortality rate of $4.3 \%$ and stroke rate of $2.5 \%$ in patients having elective proximal aortic repair with SACP is comparable to other published series. ${ }^{2,10,16,20}$ These outcomes were observed despite the complexity of the elective procedures including concomitant total aortic arch replacement, $\mathrm{CABG}$, and aortic root procedures, with a large percentage of the cases being done in the setting of reoperative cardiac surgery (Table 2).

Despite a low operative mortality and stroke rate among patients having elective surgery with SACP, our emergency outcomes were less favorable and may be related to diseasespecific factors as the majority of deaths occurred in the setting of malperfusion or rupture. The operative mortality in patients having emergency surgery for acute type A aortic dissection was $20 \%$. In contrast, Bavaria and colleagues ${ }^{8,9}$ have instituted a standardized, integrated approach for management of acute type A dissection and report in-hospital mortality rates of $<10 \%$. In their latest study, $17 \%$ of patients had aortic root replacement and $15 \%$ were reoperations. ${ }^{8}$ In this report, patients having emergency repair for type A aortic dissection included patients requiring concomitant CABG in $18.1 \%(19 / 105)$, redo sternotomy in $6.7 \%$ (7/105), aortic root reconstruction in $29.5 \%(31 / 105)$, and aortic valve replacement in 3.8\% (4/105). Our institution does not use a standardized, integrated approach for type A dissection, which may account for the improvements in survival reported by Bavaria and colleagues. ${ }^{8,9}$

\section{LIMITATIONS}

The main limitations of this study are the small sample size and retrospective nature, which limits direct comparisons between SACP and DHCA groups as well as emergency and elective groups. To detect a statistically significant difference in a relatively uncommon complication such as stroke or TND would require a much larger sample size than is presented in this analysis. Although we attempted to control for preoperative and intraoperative variables using propensity score methods, as well as univariable and multivariable comparisons, this may not fully account for the differences among these highly complex patients. Furthermore, the heterogeneity of this study population (emergency status, reoperative and concomitant procedures) makes statistical comparison difficult. Although a more homogenous patient population may allow for more accurate comparisons, we wanted to provide both raw and adjusted outcomes of all patients having proximal aortic surgery within Emory-affiliated institutions, both in the elective and emergency setting. In addition, we cannot fully account for the improvement in survival with 
the use of SACP in the elective setting because there were no statistically detectable neurologic differences; thus the mechanism for these differences can only be postulated at best. Although our elective outcomes were excellent in the SACP group, the mortality in the elective DHCA was much higher than expected, and thus the statistical differences that were observed between these groups may be misleading. Despite the complexity of the DHCA group, the elective mortality was unusually high. However, because this group consisted of only 26 patients, drawing definitive conclusions about elective proximal aortic surgery with DHCA is limited. Finally, although 9 different surgeons performed these operations, the majority $(71 \%)$ were performed by 1 person. However, we attempted to control for this selection bias by including surgeon identity in the propensity score analysis. Despite using this advanced statistical methodology, it is possible that a type II error exists given the relatively small sample size in this study.

In conclusion, we believe that SACP via the right axillary artery is a useful adjunct for cerebral protection as well as arterial inflow during surgery on the proximal thoracic aorta. This strategy allows for safe arterial access while avoiding aortic manipulation and provides a means for antegrade cerebral perfusion during circulatory arrest. Although our data do not allow definitive conclusions regarding neurologic outcomes, these patients required less time on the ventilator and in the intensive care unit and had fewer pulmonary and renal complications. Outcomes after emergency aortic repair appear to be more related to patient- and disease-specific factors rather than method of cerebral protection. On the contrary, SACP during elective surgery may be more beneficial during these potentially complex reconstructions by minimizing TND, profound hypothermia, and cardiopulmonary bypass times, which may cumulatively reduce postoperative pulmonary and renal complications. For both elective and emergency operations on the proximal thoracic aorta, improvements in surgical technique, cerebral monitoring and protection, as well as perioperative critical care will likely improve outcomes in these complex cardiac surgical patients.

We thank Clinical Research Unit director Kim Baio for project oversight, Jean Walker and Susan Joyce for data abstraction, and Deborah Canup for database management.

\section{References}

1. Ergin MA, Griepp EB, Lansman SL, Galla JD, Levy M, Griepp RB. Hypothermic circulatory arrest and other methods of cerebral protection during operations on the thoracic aorta. J Card Surg. 1994;9:525-37.

2. Hagl C, Ergin MA, Galla JD, Lansman SL, McCullough JN, Spielvogel D, et al. Neurologic outcome after ascending aorta-aortic arch operations: effect of brain protection technique in high-risk patients. J Thorac Cardiovasc Surg. 2001; 121:1107-21.

3. Reece TB, Tribble CG, Smith RL, Singh R, Stiles BM, Peeler BB, et al. Central cannulation is safe in acute aortic dissection repair. $J$ Thorac Cardiovasc Surg. 2007; 133:428-34

4. Fusco DS, Shaw RK, Tranquilli M, Kopf GS, Elefteriades JA. Femoral cannulation is safe for type A dissection repair. Ann Thorac Surg. 2004;78:1285-9.
5. Di Eusanio M, Schepens MAAM, Morshuis WJ, Di Bartolomeo R, Pierangeli A, Dossche KM. Antegrade selective cerebral perfusion during operations on the thoracic aorta: factors influencing survival and neurologic outcome in 413 patients. J Thorac Cardiovasc Surg. 2002;124:1080-6.

6. Staunch JT, Spielvogel D, Lauten A, Lansman SL, McMurtry K, Bodian CA, et al. Axillary artery cannulation: routine use in ascending aorta and aortic arch replacement. Ann Thorac Surg. 2004;78:103-8.

7. Di Eusanio M, Wesselink RMJ, Morshuis WJ, Dossche KM, Schepens MAAM Deep hypothermic circulatory arrest and antegrade selective cerebral perfusion during ascending aorta-hemiarch replacement: a retrospective comparative study. J Thorac Cardiovasc Surg. 2003;125:849-54.

8. Bavaria JE, Brinster DR, Gorman RC, Woo YJ, Gleason T, Pochettino A. Advances in the treatment of acute type A dissection: an integrated approach. Ann Thorac Surg. 2002;74:S1848-52.

9. Bavaria JE, Pochettino A, Brinster DR, Gorman RC, McGarvey ML, Gorman JH, et al. New paradigms and improved results for the surgical treatment of acute type A dissection. Ann Surg. 2001;234:336-43.

10. Khaladj N, Shrestha M, Meck S, Peterss S, Kamiya H, Kallenbach K, et al. Hypothermic circulatory arrest with selective antegrade cerebral perfusion in ascending aortic and aortic arch surgery: a risk factor analysis for adverse outcome in 501 patients. J Thorac Cardiovasc Surg. 2008;135:908-14.

11. Westaby S, Katsumata T, Vaccari G. Arch and descending aortic aneurysms: in fluence of perfusion technique on neurologic outcome. Eur J Cardiothorac Surg. 1999; 15:180-5.

12. Ergin MA, Uysal S, Reich DL, Apaydin A, Lansman SL, McCullough JN, et al. Temporary neurologic dysfunction after deep hypothermic circulatory arrest: a clinical marker of long-term functional deficit. Ann Thorac Surg. 1999;67:1887-94.

13. Molenberghs G, Kenward MG. Missing Data in Clinical Studies. West Sussex England: John Wiley and Sons; 2007.

14. Budde JM, Serna DL, Osborne SC, Steele MA, Chen EP. Axillary cannulation for proximal aortic surgery is as safe in the emergent setting as in elective cases. Ann Thorac Surg. 2006;82:2154-60.

15. Kazui T, Yamashita K, Washiayama N, Terada H, Bashar AH, Suzuki T, et al. Usefulness of antegrade selective cerebral perfusion during aortic arch operations. Ann Thorac Surg. 2002;74:1806S-9S.

16. Svensson LG, Blackstone EH, Rajeswaran J, Sabik JF, Lytle BW, GonzalezStawinski G, et al. Does the arterial cannulation site for circulatory arrest influence stroke risk? Ann Thorac Surg. 2004;78:1274-84.

17. Kazui T, Washijama N, Muhammad BAH, Terada H, Yamashita K, Takinami M et al. Total arch replacement using aortic arch branched grafts with the aid of antegrade selective cerebral perfusion. Ann Thorac Surg. 2000;70:3-9.

18. Hagl C, Khaladj N, Karck M, Kallenbach K, Leyh R, Winterhalter M, et al. Hypothermic circulatory arrest during ascending and aortic arch surgery: the theoretical impact of different cerebral perfusion techniques and other methods of cerebral protection. Eur J Cardiothorac Surg. 2003;24:371-8.

19. Kamiya H, Hagl C, Kropivnitskaya I, Bothig D, Kallenbach K, Khaladj N, et al. The safety of moderate hypothermic lower body circulatory arrest with selective cerebral perfusion: a propensity score analysis. J Thorac Cardiovasc Surg. 2007; 133:501-9.

20. Appoo JJ, Augoustides JG, Pochettino A, Savino JS, McGarvey ML, Cowie DC, et al. Perioperative outcome in adults undergoing elective deep hypothermic circulatory arrest with retrograde cerebral perfusion in proximal aortic arch repair: evaluation of protocol-based care. J Cardiothorac Vasc Anesth. 2006;20:3-7.

21. Harrington DK, Walker AS, Kaukuntla H, Bracewell RM, Clutton-Brock TH Faroqui M, et al. Selective antegrade cerebral perfusion attenuates brain metabolic deficit in aortic arch surgery: a prospective randomized trial. Circulation. 2004; 110(11 Suppl I): II231-6.

22. Reich DL, Uysal S, Sliwinski M, Kahn RA, Konstadt SN, McCullough J, et al. Neuropsychologic outcome after deep hypothermic circulatory arrest in adults. J Thorac Cardiovasc Surg. 1999;117:156-63.

\section{Discussion}

Dr Joseph Bavaria (Philadelphia, Pa). I want to thank the Association as well as Dr Chen for this work. This contemporary series from Dr Chen at Emory contributes to the now nearoverwhelming knowledge base that circulation management during open aortic arch procedures using adjunctive cerebral protection 
concepts, which in this case is antegrade cerebral perfusion, is superior to deep hypothermic circulatory arrest alone. I have a few questions after reading the manuscript for Dr Chen.

The first is, your elective SACP results are outstanding, with a mortality rate of $4.3 \%$ and a permanent cardiovascular accident risk of $2.9 \%$. This is in the paper. On the other hand, your elective deep hypothermic circulatory arrest alone results were quite poor, at $23.1 \%$ mortality, which was actually higher than the emergency group. Why do you think there was such a disparity?

Dr Chen (Atlanta, Ga). Thank you, Dr Bavaria. We were disappointed and somewhat puzzled by those results. I can tell you that we were very conservative in categorizing elective versus emergency. Because the numbers were low, we were able to look at the 6 deaths in the elective group. Two of those patients were having elective procedures but had an intraoperative unexpected aortic emergency, which was not able to be repaired primarily, necessitating an aortic replacement. Those were 2 patients that we chose to leave in the elective group. Other patients were all very high risk. One patient was 6 weeks postoperative from a type A dissection with renal failure, was heparin-induced thrombocytopenia positive, and had an infected graft with ongoing low-grade sepsis that needed an operative procedure, and then 2 others were multiple operations in patients who had had reoperative surgery in the setting of either aortic calcification or aneurysmal disease. The patients who did not survive were, in our mind, very high risk. And because the numbers in the overall denominator were low, that may explain some of those results.

Dr Bavaria. The second question. And really, it should be noted that this series is a combination of an emergency series and an elective series, and they really should be analyzed independently. Your emergency acute type A aortic dissection results showed no difference between the DHCA group and the SACP group. The emergency mortality was between $18.5 \%$ and $22.5 \%$ for those 2 groups, respectively. Why do you think the circulation management choice did not impact results in the emergency group as it did in the elective group?

Dr Chen. We were also disappointed in those results. As you have published in the past, an integrated approach to acute type A dissection results in lower and improved operative mortality. We do not employ such an approach in the Emory health care system. If you examine our deaths individually, these were all very complicated dissections. Only in the 12 operative deaths did 1 patient have a successful procedure and died of prolonged hospitalization. Several had severe forms of malperfusion, rupture. One young patient even had a ruptured papillary muscle after going home, another one ruptured at home. So, in our mind, these patients had presented with very complicated forms of dissection, which may explain some of their demise.

Dr Bavaria. My last question

Dr D. Craig Miller (Stanford, Calif). Joe, wait a second. I am going to help defend Dr Chen. How about a little beta or type II error effect, too? It is a smallish number of patients. Maybe you could not exhibit a difference there because of the sample size and the scatter?

Dr Bavaria. Maybe. I think their results were actually statistically significant, though.

Dr Miller. No, just in that acute A group.

Dr Bavaria. Yes, right, and possibly they were not significant. Dr Miller. Sorry to interrupt.
Dr Bavaria. That's all right.

Dr Miller. You didn't even thank me, Ed.

Dr Chen. Thank you, sir.

Dr Bavaria. That was a good answer.

This is something that Dr Miller has actually talked about, as well as myself, and this next question is highly charged and political. I know this is controversial and I also know that you have to go back to Atlanta, but nevertheless, I was intrigued by the fact that this was a summary of 3 "open heart" hospitals in the overall Emory system. We at Penn have similar issues. Is there "uncovered" data in this analysis that would suggest either in the elective but especially the emergency cases that high-volume hospitals with well-versed "aortic arch" protocols have better results?

Dr Chen. We also would like to employ such an integrated system. Within the 3 hospitals, there are differences in volume, experience level. If you look at the overall percentage of operations performed at Emory University Hospital, over $70 \%$ of the overall patient study group, both deep hypothermia and the selective groups, were performed at Emory Hospital. If you select out the elective patients, over $90 \%$ of those were done at Emory Hospital. Having said that, however, we did not apply multivariable analysis with respect to hospital site or surgeon experience to determine whether those were independent predictors of outcome.

Dr Bavaria. I think that is a decision that Dr Guyton will have to make. Thank you very much.

Dr Charles Fraser (Houston, Tex). That was an elegant presentation and a very nicely demonstrated series. As you probably know, this issue is also a subject of debate in congenital heart surgery. In fact, we had a very healthy debate between Marshall Jacobs and Jim Tweddell yesterday in our congenital session.

I wanted to ask you a mechanistic question. In your selective or antegrade cerebral perfusion patients, you chose $10 \mathrm{~mL} / \mathrm{kg}$, and I am presuming that that was just arbitrary. Do you monitor the patients' brains during the time that you are perfusing them? We know in children, albeit most children don't have atherosclerosis, they do sometimes have incomplete circle of Willis, and we have seen in a number of children if you flow less than $30 \mathrm{~mL} / \mathrm{kg}$, you have no perfusion on the left side of the brain if you are perfusing the right innominate artery. I was curious, do you monitor the brains in these patients during antegrade perfusion?

Dr Chen. Yes, sir, we do. We use continuous cerebral oximetry and have electroencephalographic monitoring. The $10 \mathrm{~mL} \cdot \mathrm{kg}^{-1}$. $\mathrm{min}^{-1}$ was taken from the adult literature, particularly from the Japanese data-Dr Kazui, who has a very successful series of patients undergoing total arch replacement. We do like the temperature to be cold, however. And I will admit that, depending on the cerebral oximetry numbers, we may adjust the flow accordingly. I think in the adult population we have found in our experience that the right axillary artery alone is often adequate. If you clamp the left artery and pressurize the system, I think the extracranial vascular system does provide enough collateral flow, in our mind, for the majority of patients.

Dr C. Miller. Chuck, that is a good question, but Dr Kazui has excellent substantiating evidence that $10 \mathrm{~mL} \cdot \mathrm{kg}^{-1} \cdot \mathrm{min}^{-1} \mathrm{SACP}$ flow is enough; however, for the sake of completeness, Dr Kazui is perfusing both sides (and most often 3 arteries), and you are just perfusing 1 side, which is also what we do usually. We have found that perfusing 1 side at $10 \mathrm{~mL} \cdot \mathrm{kg}^{-1} \cdot \mathrm{min}^{-1}$ unilaterally 
using SACP is enough cerebral flow, even at $20^{\circ} \mathrm{C}$ to $25^{\circ} \mathrm{C}$ if the total cerebral perfusion time is under 45 minutes.

Dr F. Sellke (Boston, Mass). I have a study design question. Although your results are excellent, very consistent with conventional wisdom, were the groups performed contemporaneously, meaning was the axillary cannulation group performed at the same time as the deep hypothermic circulatory arrest group? If not, could the results be explained by attaining a learning curve as you conducted the procedures? Were most of the operations using deep hypothermic circulatory arrest performed prior to the other group?
Dr Chen. No, sir, they were not. I think that the bias at Emory has trended toward the use of the axillary artery and the use of SACP. That practice has disseminated within our group. Typically using DHCA, no matter which site one chooses for arterial access, is probably related to patient issues (ie, someone has had previous cardiac surgery and it is very difficult to access the artery or an intraoperative emergency, an aortic injury, things like that).

But to answer your original question, these cases were all done concurrently. We did not complete the deep hypothermic group and then go to the axillary. They just tended to come up depending on the individual patient situation. 